\title{
SPK UNTUK MENENTUKAN PEMBERIAN PINJAM MODAL KERJA DENGAN METODE TOPSIS (STUDI KASUS DI BANK SAHABAT SAMPOERNA)
}

\author{
Dimas Bagos Yudistira ${ }^{1}$, Ekojono ${ }^{2}$ \\ Program Studi Teknik Informatika, Jurusan Teknologi Informasi, Politeknik Negeri Malang \\ email4jobdimasbagosy@gmail.com, ${ }^{2}$ ekojono@gmail.com
}

\begin{abstract}
Abstrak
Bank Sahabat Sampoerna merupakan lembaga keuangan bank yang menerima simpanan dalam bentuk tabungan, giro dan deposito serta melayani pinjaman berupa kredit. Bank Sahabat Sampoerna memiliki permasalahan terkait dengan pengelolaan pinjaman modal kerja, seperti penentuan pengajuan apakah seseorang tersebut layak, tidak layak atau ditangguhkan mendapatkan pinjaman modal kerja. Untuk mengatasi masalah tersebut dapat dibangun Aplikasi Sistem Pendukung Keputusan Untuk Menentukan Pemberian Pinjam Modal Kerja Dengan Metode TOPSIS (Technique for Order of Preference by Similarity to Ideal Solution). Aplikasi ini memiliki fitur pengelolaan data pribadi nasabah, sistem pengambilan keputusan. Hasil dari sistem ini adalah laporan rekap peminjaman modal kerja usaha mikro. Aplikasi ini dapat membantu pihak bank sahabat sampoerna dalam memutuskan sebuah pengajuan pinjaman modal kerja layak, tidak layak, atau ditangguhkan. Dengan adanya aplikasi ini pengambilan keputusan untuk pengajuan modal kerja dapat dilakukan dengan mudah.
\end{abstract}

Kata kunci : sistem pendukung keputusan, pinjaman modal kerja, bank, bank sahabat sampoerna, TOPSIS

\section{Pendahuluan}

Bank Sahabat Sampoerna merupakan lembaga keuangan bank yang menerima simpanan dalam bentuk tabungan, giro dan deposito serta melayani pinjaman berupa kredit. Bank Sahabat Sampoerna memiliki permasalahan terkait dengan pengelolaan pinjaman modal kerja, seperti penentuan pengajuan apakah seseorang tersebut layak, tidak layak atau ditangguhkan mendapatkan pinjaman modal kerja.

Untuk menilai masing-masing nasabah, dibutuhkan suatu metode TOPSIS. Metode TOPSIS yang dirumuskan dalam penelitian ini diawali dengan penilaian kriteria pada setiap nasabah yang dilanjutkan dengan pemberian bobot pada masingmasing kriteria. Tahap selenjutnya adalah mencari nilai batas positive dan negative untuk mengukur nilai setiap nasabah dimana sebuah nilai dikatakan baik jika nilai tersebut mempunya jarak terjauh dari nilai negative dan mempunyai jarak terpendek dari nilai positive selanjutnya akan dilakukan ranking.

Tujuan penelitian ini adalah untuk membantu pihak bank mengambil keputusan untuk memberikan pinjaman modal kerja kepada nasabah

Data yang digunakan untuk memperleh hasil keputusan ini adalah data pengajuan pinjaman modal kerja di bank Sahabat Sampoerna.

\section{Tinjauan Pustaka}

\subsection{Sistem Pendukung Keputusan}

Definisi sistem pendukung keputusan adalah sistem berbasis komputer yang interaktif yang membantu pengambil keputusan memanfaatkan data dan model untuk menyelesaikan masalah-masalah yang terstruktur. Sistem pendukung keputusan ditujukan untuk keputusan yang tidak dapat didukung oleh algoritma. Diskripsi sistem pendukung keputusan harus terkomputerisasi, online, dan interaktif bahkan memungkinkan memberikan kemampuan menampilkan penyajian data secara grafis.

\subsection{Pinjaman Modal Kerja}

Pinjaman Modal Kerja yaitu pembiayaan yang diberikan kepada usaha yang sedang berkembang untuk kebutuhan modal kerja maupun investasi dalam bentuk tunai maupun non-tunai.

$$
\text { Pembiayaan ini dapat }
$$

berupa refinancing (pembiayaan kembali) menggunakan aset yang sudah dimiliki oleh nasabah. Pinjaman Modal kerja pada Bank Sahabat Sampoerna memiliki keunggulan sebagai berikut:

1. Proses cepat, praktis dan flexible.

2. Layanan perbankan personal yang selalu siap membantu Nasabah.

3. Tersedia program pinjaman yang disesuaikan dengan jenis usaha nasabah.

4. Memberikan layanan untuk meningkat nilai tambah usaha nasabah. 


\subsection{TOPSIS (Technique For Others Reference by Similarity to Ideal Solution)}

Topsis adalah salah satu metode pengambilan keputusan multikriteria yang pertama kali diperkenalkan oleh Yoon dan Hwang (1981). TOPSIS menggunakan prinsip bahwa alternatif yang terpilih harus mempunyai jarak terdekat dari solusi ideal positif dan terjauh dari solusi ideal negatif dari sudut pandang geometris dengan menggunakan jarak Euclidean untuk menentukan kedekatan relatif dari suatu alternatif dengan solusi optimal.

\subsection{Langkah-Langkah Metode TOPSIS}

Langkah-langkah metode TOPSIS (Technique For Others Reference by Similarity to Ideal Solution):

1. Membangun normalized decision matrix Elemen rij hasil dari normalisasi decision matrix $\mathrm{R}$ dengan metode Euclidean length of a vector adalah:

$$
r_{i j}=\frac{x_{i j}}{\sqrt{\sum_{i=1}^{m} x_{i j}^{2}}}
$$

2. Membuat pembobotan pada matriks yang telah dinormalisasi. Setelah dinormalisasi, setiap kolom pada matriks $\mathrm{R}$ dikalikan dengan bobotbobot (wj) untuk menghasilkan matriks.

$$
V i j=W_{i j} \quad r_{i j}
$$

3. Menentukan nilai solusi ideal positif dan solusi ideal negatif. Solusi ideal dinotasikan $A^{+}$, sedangkan solusi ideal negatif dinotasikan $A^{-}$.

Persamaan untuk menentukan solusi ideal positif.

$$
\begin{aligned}
& A^{+}=\left\{\left(\max V_{i j} \mid \mathrm{j} € \mathrm{~J}\right),\left(\min V_{i j} \mid \mathrm{j} € \mathrm{~J}^{\prime}\right), \mathrm{i}=1,\right. \\
& \quad 2,3, \ldots, \mathrm{m}\} \\
& =\left\{V_{1}^{+}, V_{2}^{+}, V_{3}^{+}, \ldots, V_{n}^{+}\right\}
\end{aligned}
$$

Persamaan untuk menentukan solusi ideal negatif.

$A^{-}=\left\{\left(\max V_{i j} \mid \mathrm{j} € \mathrm{~J}\right),\left(\min V_{i j} \mid \mathrm{j} \in \mathrm{J}^{\prime}\right), \mathrm{i}=1,2\right.$, $3, \ldots, \mathrm{m}\}$

$=\left\{V_{1}^{-}, V_{2}^{-}, V_{3}^{-}, \ldots, V_{n}^{-}\right\}$

4. Menghitung separation measure. Separation measure ini merupakan pengukuran jarak dari suatu alternatif ke solusi ideal positif dan solusi ideal negatif.

Positif

$$
D_{i}^{+}=\sqrt{\sum_{j=i}^{n}\left(v_{i j}-v_{j}^{+}\right)^{2}}
$$

$$
\begin{aligned}
& \text { Negatif } \\
& D_{i}^{-}=\sqrt{\sum_{j=i}^{n}\left(v_{i j}-v_{j}^{-}\right)^{2}}
\end{aligned}
$$

5. Menghitung

nilai preferensi untuk setiap alternatif. Untuk menentukan ranking tiap-tiap alternatif yang ada maka perlu dihitung terlebih dahulu nilai preferensi dari tiap alternatif.

$$
C_{1}=\frac{D_{i}^{-}}{D_{i}^{-}+D_{i}^{+}} \text {dengan } 0<C_{i}^{+}<1_{\text {dan }_{i=}}
$$

$$
1,2,3, \ldots, \mathrm{m}
$$

6. Meranking Alternatif

Alternatif dapat diranking berdasarkan urutan $\mathrm{Ci}$ *. Maka dari itu, alternatif terbaik adalah salah

\begin{tabular}{|c|c|c|c|c|}
\hline $\mathrm{z}$ & Kriteria & Bobot & Keterangan & Nilai \\
\hline \multirow[t]{4}{*}{1} & B.I Checking & \multirow{4}{*}{5} & Sangat Baik & 5 \\
\hline & & & Baik & 4 \\
\hline & & & Sedang & 3 \\
\hline & & & Buruk & 1 \\
\hline \multirow[t]{5}{*}{2} & SHM & \multirow{5}{*}{3} & $500 \mathrm{sd} \ldots \mathrm{m}^{2}$ & 5 \\
\hline & & & $201 \mathrm{sd} 500 \mathrm{~m}^{2}$ & 4 \\
\hline & & & $101 \mathrm{sd} 200 \mathrm{~m}^{2}$ & 3 \\
\hline & & & $51 \mathrm{sd} 100 \mathrm{~m}^{2}$ & 2 \\
\hline & & & $1 \mathrm{sd} 50 \mathrm{~m}^{2}$ & 1 \\
\hline \multirow[t]{4}{*}{3} & Letak Usaha & \multirow{4}{*}{3} & Sangat Strategis & 5 \\
\hline & & & Strategis & 4 \\
\hline & & & Cukup Strategis & 3 \\
\hline & & & Tidak Strategis & 1 \\
\hline \multirow[t]{3}{*}{4} & Pembukuan & \multirow{3}{*}{3} & Baik & 5 \\
\hline & & & Sedang & 3 \\
\hline & & & Buruk & 1 \\
\hline \multirow[t]{3}{*}{5} & Perhitungan & \multirow{3}{*}{4} & Baik & 5 \\
\hline & D.O.H & & Sedang & 3 \\
\hline & & & Buruk & 1 \\
\hline \multirow[t]{3}{*}{6} & Perhitungan & \multirow{2}{*}{4} & Baik & 5 \\
\hline & W.I Neraca & & Sedang & 3 \\
\hline & & & Buruk & 1 \\
\hline \multirow[t]{3}{*}{7} & Perhitungan & \multirow{3}{*}{4} & Baik & 5 \\
\hline & W.I Normal & & Sedang & 3 \\
\hline & & & Buruk & 1 \\
\hline \multirow[t]{2}{*}{8} & $\begin{array}{c}\text { Nilai } \\
\text { Piniaman }\end{array}$ & \multirow{2}{*}{3} & $0 \mathrm{sd} 20 \mathrm{JT}$ & 5 \\
\hline & & & $20 \mathrm{sd} 40 \mathrm{JT}$ & 4 \\
\hline
\end{tabular}
satu yang berjarak terpendek terhadap solusi ideal dan berjarak terjauh dengan solusi ideal negatif.

\section{Pembahasan}

Dalam penelitian ini menggunakan metode TOPSIS, dimana sebuah nilai keputusan di katakan baik jika nilai keputusan tersebut memiliki jarak terjauh dari nilai negative dan memiliki jarak terdekat dari nilai positive. Berikut ini adalah langkah-langkah metode TOPSIS: 


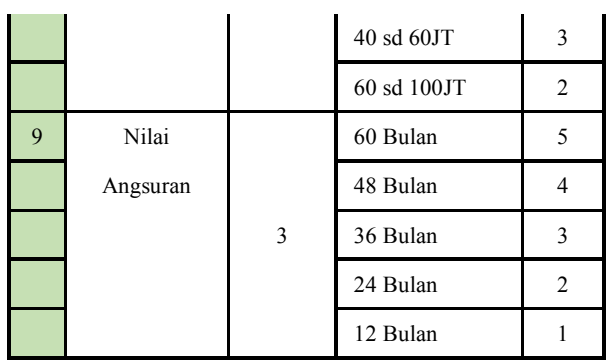

1. Membuat matriks keputusan

\begin{tabular}{|l|l|l|l|l|l|l|l|l|l|}
\hline Alternative & 1 & 2 & 3 & $\mathrm{c}$ & $\mathrm{c}$ & $\mathrm{c}$ & $\mathrm{c}$ & $\mathrm{c}$ & $\mathrm{c}$ \\
\hline Bp. Dimas & 5 & 5 & 4 & 3 & 5 & 1 & 3 & 4 & 3 \\
\hline Bp. Irawan & 4 & 4 & 3 & 3 & 3 & 3 & 5 & 4 & 3 \\
\hline Ny. Lely & 3 & 4 & 5 & 5 & 3 & 5 & 1 & 2 & 5 \\
\hline
\end{tabular}

2. Membuat matriks keputusan ternormalisasi

\begin{tabular}{|c|c|c|c|c|c|c|c|c|c|}
\hline $\begin{array}{c}\text { Alternati } \\
\text { ve }\end{array}$ & $\mathrm{cl}$ & c2 & c3 & $\mathrm{c} 4$ & c5 & $\mathrm{c} 6$ & c7 & c8 & $\mathrm{c} 9$ \\
\hline $\begin{array}{l}\text { Bp. } \\
\text { Dimas }\end{array}$ & $\begin{array}{l}0.70 \\
7\end{array}$ & $\begin{array}{c}0.66 \\
2\end{array}$ & $\begin{array}{c}0.56 \\
6 \\
\end{array}$ & $\begin{array}{c}0.45 \\
7 \\
\end{array}$ & $\frac{0.76}{2}$ & $\begin{array}{c}0.16 \\
9\end{array}$ & $\begin{array}{c}0.50 \\
7 \\
\end{array}$ & $\begin{array}{r}0.66 \\
7 \\
\end{array}$ & $\begin{array}{c}0.45 \\
7\end{array}$ \\
\hline $\begin{array}{l}\text { Bp. } \\
\text { Irawan }\end{array}$ & $\begin{array}{c}0.56 \\
6\end{array}$ & 0.53 & $\begin{array}{c}0.42 \\
4\end{array}$ & $\begin{array}{c}0.45 \\
7\end{array}$ & $\begin{array}{c}0.45 \\
7\end{array}$ & $\begin{array}{c}0.50 \\
7\end{array}$ & $\frac{0.84}{5}$ & $\begin{array}{c}0.66 \\
7\end{array}$ & $\begin{array}{c}0.45 \\
7 \\
7\end{array}$ \\
\hline Ny. Lel & $\begin{array}{c}0.42 \\
4\end{array}$ & 0.53 & $\begin{array}{c}0.70 \\
7\end{array}$ & $\begin{array}{c}0.76 \\
2\end{array}$ & $\begin{array}{c}0.45 \\
7\end{array}$ & $\begin{array}{c}0.84 \\
5\end{array}$ & $\begin{array}{c}0.16 \\
9\end{array}$ & $\begin{array}{c}0.33 \\
3\end{array}$ & $\begin{array}{c}0.76 \\
2\end{array}$ \\
\hline
\end{tabular}

3. Membuat matriks keputusan ternormalisasi terbobot

\begin{tabular}{|c|c|c|c|c|c|c|c|c|c|}
\hline $\begin{array}{l}\text { Alternati } \\
\text { ve }\end{array}$ & cl & c2 & c3 & $c$ & 5 & $c_{6}$ & C7 & $\begin{array}{l}c \\
8\end{array}$ & (9) \\
\hline $\begin{array}{l}\text { Bp. } \\
\text { Dimas }\end{array}$ & $\begin{array}{c}3.53 \\
6 \\
\end{array}$ & $\begin{array}{c}1.98 \\
7\end{array}$ & $\begin{array}{c}1.69 \\
7 \\
7\end{array}$ & $\begin{array}{c}1.37 \\
2\end{array}$ & $\begin{array}{c}3.0 \\
5 \\
\end{array}$ & $\begin{array}{c}0.67 \\
6 \\
\end{array}$ & $\begin{array}{c}2.02 \\
8\end{array}$ & 2 & $\begin{array}{c}1.37 \\
2\end{array}$ \\
\hline $\begin{array}{l}\text { Bp. } \\
\text { Irawan }\end{array}$ & $\begin{array}{c}2.82 \\
8\end{array}$ & $\begin{array}{c}1.58 \\
9\end{array}$ & $\begin{array}{c}1.27 \\
3\end{array}$ & $\begin{array}{c}1.37 \\
2\end{array}$ & $\begin{array}{c}1.8 \\
3\end{array}$ & $\begin{array}{c}2.02 \\
8\end{array}$ & $\begin{array}{c}3.38 \\
1\end{array}$ & 2 & $\begin{array}{c}1.37 \\
2\end{array}$ \\
\hline $\mathrm{Ny}$. Lely & $\begin{array}{c}2.12 \\
1\end{array}$ & $\begin{array}{c}1.58 \\
9\end{array}$ & 2.12 & $\begin{array}{c}2.28 \\
7\end{array}$ & $\begin{array}{c}1.8 \\
3\end{array}$ & $\begin{array}{c}3.38 \\
1\end{array}$ & $\begin{array}{c}0.67 \\
6\end{array}$ & 1 & $\begin{array}{c}2.28 \\
7\end{array}$ \\
\hline
\end{tabular}

4. Menentukan nilai solusi ideal positif $\left(A^{+}\right)$dan nilai solusi ideal negative $\left(A^{-}\right)$

a. Solusi ideal positive

$\mathrm{yl}^{+}=\max \{3.536 ; 2.828 ; 2.121\}=3.536$

$\mathrm{y} 2^{+}=\max \{1.987 ; 1.589 ; 1.589\}=1.987$

$\mathrm{y}^{+}=\max \{1.697 ; 1.273 ; 2.121\}=2.121$

$\mathrm{y}^{+}=\max \{1.372 ; 1.372 ; 2.287\}=2.287$

$\mathrm{y}^{+}=\max \{3.05 ; 1.83 ; 1.83\}=3.05$

$\mathrm{y}^{+}=\max \{0.676 ; 2.028 ; 3.381\}=3.381$

$\mathrm{y} 7^{+}=\max \{2.028 ; 3.381 ; 0.676\}=3.381$

$\mathrm{y} 8^{+}=\max \{2 ; 2 ; 1\}=2$

$\mathrm{y} 9^{+}=\max \{1.372 ; 1.372 ; 2.287\}=2.287$

$A^{+}=\{3.536 ; 1.987 ; 2.121 ; 2.287 ; 3.05 ; 3.381 ; 3.381 ; 2$; $2.287\}$

b. Solusi ideal negative

$\mathrm{y} 1^{-}=\min \{3.536 ; 2.828 ; 2.121\}=2.121$

$\mathrm{y} 2=\min \{1.987 ; 1.589 ; 1.589\}=1.589$

$\mathrm{y} 3=\min \{1.697 ; 1.273 ; 2.121\}=1.273$

$\mathrm{y} 4=\min \{1.372 ; 1.372 ; 2.287\}=1.372$

$\mathrm{y} 5=\min \{3.05 ; 1.83 ; 1.83\}=1.83$

$\mathrm{y}^{6}=\min \{0.676 ; 2.028 ; 3.381\}=0.676$

$\mathrm{y}^{-}=\min \{2.028 ; 3.381 ; 0.676\}=0.676$

$\mathrm{y} 8=\min \{2 ; 2 ; 1\}=1$

$\mathrm{y}^{-}=\min \{1.372 ; 1.372 ; 2.287\}=1.372$

$A^{-} \quad=\{2.121 ; 1.589 ; 1.273 ; 1.372 ; 1.83 ; 0.676 ; 0.676 ; 1$; $1.372\}$

5.Menentukan jarak antara nilai terbobot setiap alternative terhadap solusi ideal positive dan negative.

\section{a. Positive}
$\sqrt{(3.536-3.536)^{2}+(1.987-1.987)^{2}+(1.697-2.121)^{2}+}$
$(1.372-2.287)^{2}+(3.05-3.05)^{2}+(0.676-3.381)^{2}+$
$(2.208-3.381)^{2}+(2-2)^{2}+(1.372-2.287)^{2}$
$=10.54718$

$\mathrm{D} 2^{+}$
$(2.828-3.536)^{2}+(1.589-1.987)^{2}+(1.273-2.121)^{2}+$ $(1.372-2.287)^{2}+(1.83-3.05)^{2}+(2.028-3.381)^{2}+$ $(3.381-3.381)^{2}+(2-2)^{2}+(1.372-2.287)^{2}$ $=6.372231$

$\mathrm{D}^{+}$

$(2.121-3.536)^{2}+(1.589-1.987)^{2}+(2.121-2.121)^{2}+$ $(2.287-2.287)^{2}+(1.83-3.05)^{2}+(3.381-3.381)^{2}+$ $(0.676-3.381)^{2}+(1-2)^{2}+(2.287-2.287)^{2}$

$=11.966054$

\section{b. Negative}

$\mathrm{D}^{-}$ $\sqrt{\begin{array}{c}(3.536-2.121)^{2}+(1.987-1.589)^{2}+(1.697-1.273)^{2}+ \\ (1.372-1.372)^{2}+(3.05-1.83)^{2}+(0.676-0.676)^{2}+ \\ (2.208-0.676)^{2}+(2-1)^{2}+(1.372-1.372)^{2}\end{array}}$
$=7.191417$

D2-

$\sqrt{=\begin{array}{c}(2.828-2.121)^{2}+(1.589-1.589)^{2}+(1.273-1.273)^{2}+ \\ (1.372-1.372)^{2}+(1.83-1.83)^{2}+(2.028-0.67)^{2}+ \\ (3.381-0.67)^{2}+(2-1)^{2}+(1.372-1.372)^{2}\end{array}}$

D3-

$\sqrt{(2.121-2.121)^{2}+(1.589-1.589)^{2}+(2.121-1.273)^{2}+}$

$(2.287-1.372)^{2}+(1.83-1.83)^{2}+(3.381-0.676)^{2}+$ $(0.676-0.67)^{2}+(1-1)^{2}+(2.287-1.372)^{2}$

$=9.704615$

6. Menghitung nilai preferensi untuk setiap alternatif.

$$
\begin{aligned}
& C_{1}=\frac{7.191417}{7.191417+10.54718}=0.40541 \\
& C_{2}=\frac{10.693534}{10.6935334+6.372231}=0.62660 \\
& C_{3}=\frac{9.704615}{9.704615+11.966054}=0.44782
\end{aligned}
$$

7. Meranking Alternatif, lternatif dapat diranking berdasarkan urutan $\mathrm{Ci}$ *.

$\begin{array}{ll}\checkmark & \text { Ranking 1 }=\mathrm{C} 2=0.62660 \\ \checkmark & \text { Ranking 2 }=\mathrm{C} 3=0.44782 \\ \checkmark & \text { Ranking 3 }=\mathrm{C} 1=0.40541\end{array}$

\section{Implementasi}

Untuk masuk masuk ke dalam halaman utama, maka admin harus login terlebih dahulu. Jika login gagal maka akan ada pemberitahuan bahwa user ID dan password salah. Admin harus memasukkan ulang 
user ID dan password sampai database membaca benar data login yang dimasukkan.

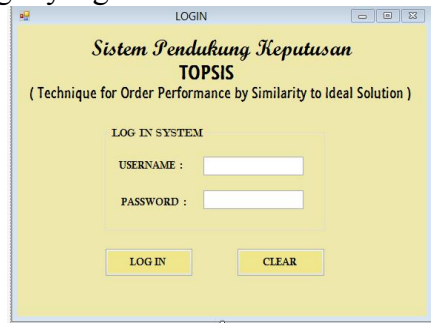

Gambar 1. Form login

Pada tampilan form menu utama ini dapat dilihat terdapat menu-menu yang dapat dipilih untuk berinteraksi dalam proses pendukung pemilihan pemberian kredit pada nasabah dengan metode TOPSIS

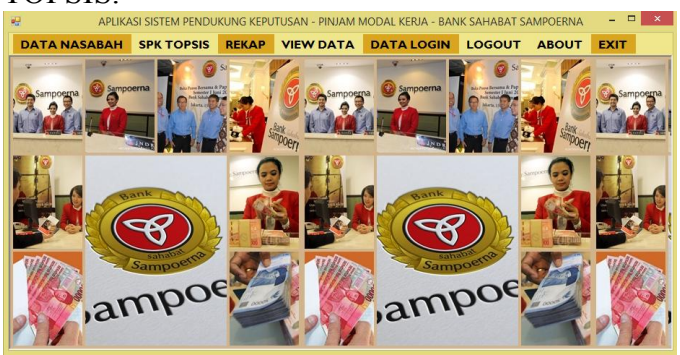

Gambar 2 Tampilan Menu Utama

Tampilan ini adalah proses pertama dalam proses perhitungan metode TOPSIS yaitu memasukan data pengajuan baru dan akan dibandingkan oleh siapa.

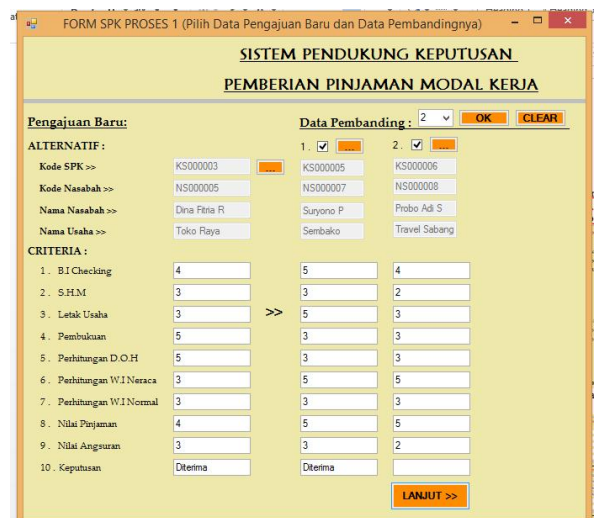

Gambar 3 Tampilan Proses 1 SPK

Setelah melalui semua tahapan proses perhitungan metode Topsis didapatkan hasil dan dari hasil ini admin dapat menganalisa apakah pengajuan ini diterima, ditangguhkan atau ditolak. Meskipun sistem ini menampilkan keputusan tetapi keputusan dari sistem ini hanya sebagai bahan pertimbangan saja dan untuk menguatkan keputusan admin.

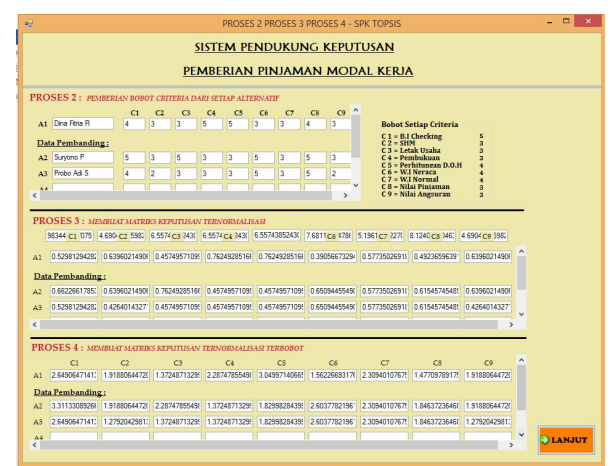

Gambar 4. Tampilan Proses 2,3 dan 4 SPK

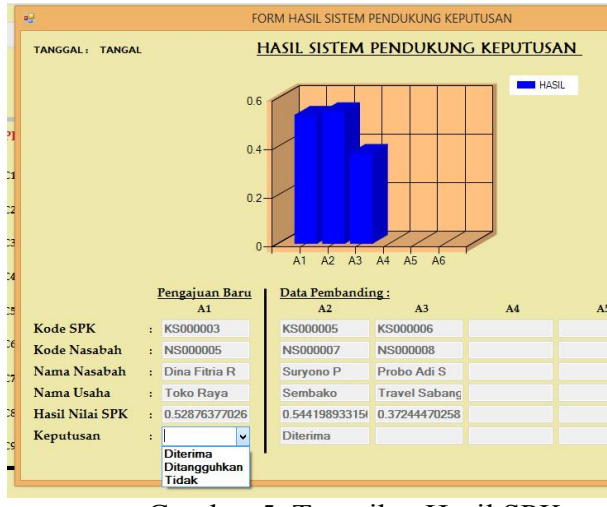

Gambar 5. Tampilan Hasil SPK

\section{Kesimpulan dan Saran}

\subsection{Kesimpulan}

Dari hasil pembuatan Aplikasi Sistem Pendukung Keputusan untuk menentukan Pinjaman Modal Kerja dengan Metode TOPSIS di Bank Sahabat Sampoerna ini didapatkan kesimpulan sebagai berikut,

Dengan adanya Sistem Pendukung Keputusan ini Pihak Bank Sahabat Sampoerna khususnya Kepala Cabang dapat dengan mudah mendapatkan keputusan untuk menerima atau tidak pengajuan pinjaman oleh nasabahnya. Adanya Sistem Pendukung Keputusan ini membuat kinerja Bank Sahabat Sampoerna lebih cepat dan tepat dalampengambilan keputusan tersebut.

Hasil dari Sistem Pendukung Keputusan ini hanya untuk menguatkan keputusan kepala cabang dimana hasil dari aplikasi di bandingkan dengan hasil analisa manual oleh Kepala Cabang. Pada kasus tertentu Kepala Cabang bisa menganalisa lebih dari dua kali dlaam satu kasus dengan adanya aplikasi ini Kepala Cabang dapat lebih cepat dalam mengambil keputusan. 


\subsection{Saran}

Saran yang diberikan untuk pengembangan penelitian ini adalah:

1. Sistem Aplikasi ini bisa di kembangkan dengan merubah framework berbasis desktop menjadi berbasis web.

2. Aplikasi bisa digabungkan dengan Web Sistem Informasi yang ada di Bank Sahabat Sampoerna Kota Blitar, jadi Kepala Cabang bisa menggunakan aplikasi dimana dan kapan saja.

\section{Daftar Pustaka:}

Tiray Putri Sari Op, 2013, Aplikasi Sistem Pendukung Keputusan Untuk Menentukan Pemberian Kredit Modal Kerja(KMK) Dengan menggunakan Metode Teqhique For Order Preference By Similarity To Ideal Soloution. Jurnal Informatika. Volume 5. No. 3. www.pelitainformatika.com. Diakses 13 Desember 2014 pukul 20.00 WIB.
Radiant Victor Imbar, Benny Setiadi Hartanto, 2011, Aplikasi Sistem Informasi Sumber Daya Manusia Dengan Fitur DSS Menggunakan Metode Topsis. Jurnal Informatika. Volume 7. No. 2. repository.maranatha.edu/1340/. Diakses 13 Desember 2014 pukul 20.15 WIB.

Tulus Subagio, 2010, Aplikasi Kelayakan Pemberian Kredit Untuk Calon Nasabah Menggunakan Metode Topsis(Studi Kasus PT.BPR Puri seger Sentosa). Jurnal TA. Volume 5. No. 3. digilib.upnjatim.ac.id. Diakses 20 Desember 2014 pukul 13.00 WIB.

Desi Leha Kurniasih, 2013, Sistem Pendukung Keputusan Pemilihan Laptop Dengan Metode Topsis. Jurnal Informatika. Volume 3. No. 2. www.pelita-informatika.com. Diakses 10 Jauniari 2015 pukul 17.00 WIB.

Budi S, 2006, Perancangan dan Pembangunan Sistem Informasi. Yogyakarta.

Kusrini, 2007, Konsep dan Aplikasi Sistem Pendukung Keputusan, CV Andi Offset, Yogyakarta. 